\title{
Papers
}

\section{Larks and owls and health, wealth, and wisdom}

\author{
Catharine Gale, Christopher Martyn
}

\begin{abstract}
Objective To test the validity of Benjamin Franklin's maxim "early to bed and early to rise makes a man healthy, wealthy, and wise."

Design Cross sectional analysis of sleeping patterns in a nationally representative group of elderly people, and longitudinal investigation of mortality.

Setting Eight areas in Britain (five in England, two in Scotland, and one in Wales).

Subjects 1229 men and women aged 65 and over who in 1973-4 had taken part in a survey funded by the Department of Health and Social Security and for whom data on sleeping patterns, health, socioeconomic circumstances, and cognitive function had been recorded.

Main outcome measures Self reported income, access to a car, standard of accommodation, performance on a test of cognitive function, state of health and mortality during 23 years of follow up. Results 356 people (29\%) were defined as larks (to bed before $11 \mathrm{pm}$ and up before $8 \mathrm{am}$ ) and 318 (26\%) were defined as owls (to bed at or after $11 \mathrm{pm}$ and up at or after $8 \mathrm{am}$ ). There was no indication that larks were richer than those with other sleeping patterns. On the contrary, owls had the largest mean income and were more likely to have access to a car. There was also no evidence that larks were superior to those with other sleeping patterns with regard to their cognitive performance or their state of health. Both larks and owls had a slightly reduced risk of death compared with the rest of the study sample, but this was accounted for by the fact that they spent less time in bed at night. In the study sample as a whole, longer periods of time in bed were associated with increased mortality. After adjustment for age, sex, the presence of illness, and other risk factors, people who spent 12 or more hours in bed had a relative risk of death of 1.7 (1.2 to 2.5) compared with those who were in bed for 9 hours. The lowest risk occurred in people who spent 8 hours in bed (adjusted relative risk $0.8 ; 0.7$ to 1.0 ).

Conclusion These findings do not support Franklin's claim. A "late to bed and late to rise" lifestyle does not seem to lead to socioeconomic, cognitive, or health disadvantage, but a longer time spent in bed may be associated with increased mortality.
\end{abstract}

\section{Introduction}

The American polymath Benjamin Franklin coined the maxim "early to bed and early to rise makes a man healthy, wealthy, and wise" and published it in Poor Richard's Almanack during the 18th century. It continues to irritate people with owlish circadian rhythms and children trying to negotiate a late bedtime. Is the explicit promise of reward in exchange for what might be a painful readjustment to a lark-like way of life justified? And how large are the expected benefits? These questions could not be answered by a search of biomedical and social science databases. Although there is a large literature on the scientific investigation of sleep, almost none is relevant to the possible influence of sleeping patterns on health outcomes, affluence, or sagacity.

Advice about lifestyle needs more to recommend it than a simple rhyme and the ease with which it trips off the tongue. In an attempt to substantiate Franklin's gnomic wisdom with evidence, we used data collected in a survey of elderly people to examine the effects of time of going to bed and time of getting up on health, material circumstances, and cognitive function.

\section{Methods}

During 1973 and 1974, the Department of Health and Social Security randomly sampled 1775 people in eight areas of Great Britain (five in England, two in Scotland, and one in Wales) using family practitioner committee lists of all patients aged 65 and over. The areas were Islington, Harrow, Hastings, Bristol, Salford, Rutherglen, Angus, and Merthyr Tydfil. Stratified sampling was used to obtain equal numbers of men and women aged 65 to 74 and 75 and over.

Of those selected, 1688 people were living in private households and were asked to take part in the study; $1419(84 \%)$ agreed. They were visited by an interviewer who administered a questionnaire on their socioeconomic circumstances and assessed the overall standard of their accommodation, with reference to the availability of piped water, hot water, cooking facilities, and heating. The interviewer also asked about their sleeping habits - the time participants usually got up and the time they usually went to bed. The last or current occupation of the participant or the husband (if the participant was a woman) was used to determine social class in accordance with the registrar general's classification of occupations (1970). In total, $983(69 \%)$ of those who were interviewed agreed to be examined by a geriatrician. The geriatricians measured height, weight, and blood pressure and recorded, after a full examination, whether they considered the participant to be healthy. Participants were also asked to state whether they judged their state of health to be good, fair, or poor. The geriatricians

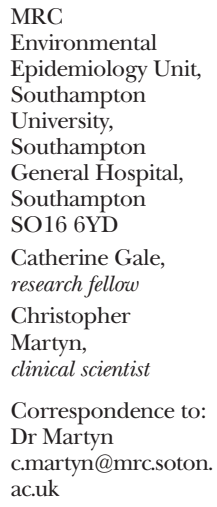

BMJ 1998;317:1675-7 
Table 1 Indicators of socioeconomic status according to sleep patterns. Values are numbers (percentages) unless otherwise indicated

\begin{tabular}{lcccc} 
& $\begin{array}{c}\text { Larks } \\
(\mathbf{n = 3 5 6 )}\end{array}$ & $\begin{array}{c}\text { Owls } \\
(\mathbf{n = 3 1 8 )}\end{array}$ & $\begin{array}{c}\text { 0ther sleeping } \\
\text { patterns } \\
(\mathbf{n}=\mathbf{5 5 5})\end{array}$ & P value $^{\text {* }}$ \\
\hline $\begin{array}{l}\text { Geometric mean (geometric SD) total weekly } \\
\text { income (£) after deduction of housing costs }\end{array}$ & $12.5(2)$ & $13.1(2)$ & $12.3(2)$ & 0.32 \\
\hline Access to car & $122(34)$ & $138(43)$ & $213(38)$ & 0.06 \\
\hline Indoor lavatory & $322(92)$ & $303(96)$ & $516(93)$ & 0.10 \\
\hline Good standard of accommodation & $255(72)$ & $230(73)$ & $416(73)$ & 0.76 \\
\hline Non-manual social class & $107(32)$ & $99(33)$ & $176(33)$ & 0.91 \\
\hline *B Bnalysis of variance or $\chi^{2}$ analysis. & & & &
\end{tabular}

assessed the participants' cognitive function by using the Hodkinson abbreviated mental test. This is a short test designed to provide an indication of cognitive impairment. ${ }^{1}$ Participants were classified into three groups according to their score on the test: those who scored the maximum of 10 points; those who scored 8 or 9 (slight impairment); and those who scored 7 or less (more severe impairment).

Of the 1419 participants who were interviewed at home, $1346(95 \%)$ were subsequently traced through the NHS central register, and death certificates were obtained for those who had died. Information on sleeping habits was available for 1229 (91\%) of these people. None of them was bed bound.

We used analysis of variance, $\chi^{2}$ tests, and logistic regression to examine the relations between sleeping habits, socioeconomic circumstances, and cognitive function. A Cox's proportional hazards model was used to examine the associations between time spent in bed and mortality. As described above, data from the geriatricians' examinations were missing for some of the study sample, so the analysis of cognitive function and the multivariate mortality analysis are based on 862 subjects. "Larks" were defined as people who went to bed before $11 \mathrm{pm}$ and got up before $8 \mathrm{am}$. "Owls" were defined as people who went to bed at or after $11 \mathrm{pm}$ and got up at or after $8 \mathrm{am}$. These definitions, although arbitrary, have been used in previous studies of individual differences in circadian rhythms. ${ }^{2}$ Risk estimates were adjusted for sex and age in five year strata (because of small numbers a 10 year stratum was used for the oldest age group). The mortality analysis is based on deaths that occurred up to 31 January 1998. The frequency distribution of weekly income was skewed and was transformed to normality by using logarithms.

\section{Results}

Of the 1229 men and women who provided information on their sleeping patterns, $356(29 \%)$ were larks and $318(26 \%)$ were owls. The proportion of men

Table 2 Relative risks (95\% confidence intervals) of all cause mortality according to number of hours spent in bed

\begin{tabular}{|c|c|c|c|c|}
\hline \multirow[b]{2}{*}{ No of hours in bed } & \multirow{2}{*}{$\begin{array}{c}\text { No of } \\
\text { subjects }\end{array}$} & \multirow{2}{*}{$\begin{array}{l}\text { No of } \\
\text { deaths }\end{array}$} & \multicolumn{2}{|c|}{ Relative risk ( $95 \% \mathrm{Cl}$ ) } \\
\hline & & & Age and sex adjusted & Multivariate adjusted ${ }^{*}$ \\
\hline$\leqslant 7$ & 69 & 63 & 1.1 (0.8 to 1.4$)$ & $1.0(0.7$ to 1.4$)$ \\
\hline 8 & 192 & 179 & $0.9(0.7$ to 1.0$)$ & $0.8(0.7$ to 1.0$)$ \\
\hline 9 & 403 & 373 & 1.0 & 1.0 \\
\hline 10 & 345 & 330 & $1.2(1.0$ to 1.4$)$ & $1.2(1.0$ to 1.4$)$ \\
\hline$\overline{11}$ & 151 & 144 & 1.5 (1.2 to 1.8$)$ & $1.3(1.0$ to 1.7$)$ \\
\hline$\geqslant 12$ & 69 & 69 & 1.9 (1.4 to 2.5$)$ & 1.7 (1.2 to 2.5$)$ \\
\hline
\end{tabular}

*Multivariate analysis based on 862 subjects seen by a geriatrician. Adjusted for age, sex, geriatrician's diagnoses of illness, social class, systolic blood pressure, and body mass index. and women in each sleeping pattern group was similar. The owls tended to be younger than either the larks or the rest of the study sample (73.9 years (SD 5.6) years $v$ 75.2 (6.1) years and $75.4(6.5)$ years respectively). There was no indication that larks were richer than those with other sleeping patterns (table 1). On the contrary, owls had the largest mean self reported income and were most likely have an indoor lavatory and access to a car, though only the latter difference approached significance.

The Hodkinson abbreviated mental test was carried out on the $862(70 \%)$ men and women in the study sample who agreed to be examined by a geriatrician. There was no difference between the sleeping pattern groups in the proportion who agreed to this assessment. Cognitive performance among larks was no better than among those with different sleeping habits: 168 (68\%) gained the maximum score of 10 points compared with $156(69 \%)$ of the owls and $253(65 \%)$ of the rest of the study sample. Because owls were, on average, slightly younger than those with other sleeping patterns, we used a logistic regression model to examine the likelihood of scoring less than 10, adjusting for age. The groups did not differ significantly.

At the time of the survey in 1973-4, there was no indication that the larks differed from subjects with other sleeping habits as regards their state of health, whether self reported or as assessed by the geriatricians.

During the 23 years of follow up, 1158 of the 1229 people in the study sample died. After adjustment for age and sex, mortality from all causes was slightly lower in both the larks and the owls than in the rest of the study sample. The relative risk of death in the larks was 0.9 (0.6 to 1.0$)$ and in the owls 0.9 (0.8 to 1.0$)$.

We investigated whether the duration of time spent in bed influenced risk of death in case this explained the differences in mortality between larks, owls, and those with other sleeping patterns. In the study sample as a whole, the median number of hours spent in bed was 9 (range 6 to 14). Time spent in bed tended to be longer at older ages, in people with a lower body mass index, in women, in people from manual social classes, and in those whom the geriatricians had diagnosed as ill. Over the 23 year follow up period, subjects who reported spending longer in bed had an increased risk of death (table 2). After adjustment for age and sex, the relative risk of death for those who were in bed for 12 hours or more compared with those who were in bed for 9 hours was 1.9 (1.4 to 2.5). The lowest risk of death occurred in people who spent 8 hours in bed (relative risk $0.9 ; 0.7$ to 1.0 ). The relation between mortality and time spent in bed persisted after further adjustment for systolic blood pressure, body mass index, social class, and the presence of illness at the time of the baseline examination by a geriatrician (table 2). These estimates of risk were little changed when the analysis was repeated after exclusion of all those whom the geriatricians had diagnosed as ill and all who died during the first 5 years of follow up.

On average, the larks spent 9.0 hours in bed, the owls spent 9.2 hours in bed, and those with other sleeping patterns were in bed for 9.8 hours $(\mathrm{P}<0.001)$. When we repeated the mortality analysis adjusting for duration of time spent in bed, the lower risk of death seen in larks and owls disappeared. 


\section{Discussion}

In this study of elderly people, those who spent longer than 8 hours in bed each night had an increased risk of death. This relation was little affected by adjustment for the presence of illness at the time of the survey (table 2). It remained significant even after the exclusion of all those whom the geriatricians had diagnosed as ill and those who had died in the first 5 years of follow up, so it seems unlikely that it simply reflects the fact that sick people tend to spend longer in bed. A similar association has been described in previous studies, ${ }^{3-5}$ though the period of follow up in these was considerably shorter. The underlying biological mechanism is unknown.

\section{A cautious interpretation}

We found no evidence, however, that following Franklin's advice about going to bed and getting up early was associated with any health, socioeconomic, or cognitive advantage. If anything, owls were wealthier than larks, though there was no difference in their health or wisdom. But these findings must be interpreted cautiously. Firstly, the analyses regarding the relation between sleeping patterns and wealth or wisdom were cross sectional and not longitudinal. The direction of cause and effect is not certain. Secondly, although we were able to use a number of indicators of social and economic status to investigate the relation between sleeping patterns and wealth, there was only the score on a short test of cognitive function with which to measure wisdom. This score probably fails to encompass the full meaning of the word "wise." Thirdly, the subjects in the study were all aged 65 years or older. There is some evidence that people tend to shift towards more lark-like habits as they get older. ${ }^{6}$ Whether our results apply to younger age groups is uncertain.

\section{Folk wisdom}

Although folklore about sleep and sleeping patterns is inconsistent, most sayings, stories, and instances seem



Healthy, wealthy, and ...?

\section{Key messages}

- Proverbial advice about lifestyle has the authority of tradition and the merit of brevity, but it is rarely based on systematically collected evidence

- In a nationally representative cohort of elderly people there was no indication that those who lived by the maxim "early to bed and early to rise" were advantaged as regards state of health, material circumstances, or wisdom

- Sleeping for more than 8 hours a night was associated with increased mortality, but it mattered little whether sleep was taken in the early or late part of the night

- There is no justification for early risers to affect moral superiority

to run parallel with Franklin's maxim. Early rising and not sleeping for too long is seen as a recipe for worldly success and even to confer moral superiority. Thomas Edison believed that too much sleep was bad for health and slowed the progress of civilisation. ${ }^{7}$ Appropriately enough, he invented the electric lightbulb. Margaret Thatcher, an exemplar of vigour and decisiveness, famously needed little sleep. And Samuel Johnson cautioned that "nobody who does not rise early will ever do any good," though the force of this advice is rather diminished by his admission that he invariably lay in bed till noon himself. ${ }^{8}$ On the other hand, there are proverbial warnings about not burning the candle at both ends and Shakespearian allusions to the restorative powers of sleep. In Henry $I V$, sleep is described as "nature's soft nurse" and in Macbeth as "chief nourisher in life's feast" and as "knit[ing] up the ravell'd sleave of care."

Our results suggest that, though it may be wise not to spend much more than 8 hours in bed each night, the time of going to bed and getting up matters little. It seems that owls need not worry that their way of life carries adverse consequences. However, those who cite Franklin's maxim to encourage their children to go to bed early may wish to consider whether their practice is entirely ethical.

We thank the Department of Health for allowing us to use data from the 1973-4 Department of Health and Social Security nutritional survey and Paul Winter of the MRC Environmental Epidemiology Unit for computing assistance. The survey was coordinated by the late Professor A N Exton-Smith.

Contributors: CG conceived the study and analysed the data; $\mathrm{CG}$ and $\mathrm{CM}$ jointly wrote the paper.

Funding: None.

Competing interests: None declared.

1 Hodkinson HM. Evaluation of a mental test score for assessment of mental impairment in the elderly. Age Ageing 1972;1:233-8.

2 Smith CS, Reilly Q, Midkiff K. Evaluation of three circadian rhythm questionnaires with suggestions for an improved measure of morningness. J Appl Psychol 1989;74:728-38.

3 Qureshi AI, Giles WH, Croft JB, Bliwise DL. Habitual sleep patterns and risk for stroke and coronary heart disease: a 10-year follow-up from NHANES I. Neurology 1997;48:904-11.

4 Ruigomez A, Alonzo J, Anto JM. Relationship of health behaviours to five-year mortality in an elderly cohort. Age Ageing 1995;24:113-9.

5 Wingard DL, Berkman LF, Brand RJ. A multivariate analysis of health-related practices: a nine-year mortality follow-up of the Alameda county study. Am J Epidemiol 1982;116:765-75.

6 Minors D, Atkinson G, Bent N, Rabbitt P, Waterhouse J. The effects of age upon some aspects of lifestyle and implications for studies on circadian rhythmicity. Age Ageing 1998;27:67-72.

7 Edison TA. The diary and sundry observations of Thomas Alva Edison. New York: Philosophical Library, 1948:52, 178. (D D Runes, ed.)

8 Boswell J. Life of Johnson.Vol 5. Oxford: Clarendon Press, 1934:299. (L F Powell's revision of G B Hill's edition.) 